\title{
REVIEW
}

\section{Genetic aspects in sarcoidosis}

\author{
M. Luisetti*, A. Beretta*, L. Casali*,\#
}

Genetic aspects in sarcoidosis. M. Luisetti, A. Beretta, L. Casali. (C)ERS Journals Ltd 2000. ABSTRACT: Sarcoidosis is an immune-mediated, multiorgan, granulomatous disorder thought to be triggered by an intricate combination of environmental and genetic factors. Two robust lines of evidence support the hypothesis of a genetic component in the pathogenesis of sarcoidosis: racial variation in its epidemiology and familial clustering of cases. The relationship between epidemiology and environmental factors affecting variations in sarcoidosis incidence/prevalence and presentation are reviewed, as well as strategies to be pursued in the search for susceptibility genes for the disorder.

Pathogenic processes leading to sarcoid granuloma formation and maintenance have prompted investigators interested in the genetics of sarcoidosis to focus mainly on major histocompatibility complex genes, and indeed a remarkable amount of data has been accumulated during the last two decades. Whilst in contrast with some autoimmune disorders a clear association between human leukocyte antigen (HLA) and sarcoidosis is still a controversial issue, there is, however, a general agreement that some HLA genes are related to phenotypic variations of the disease. Some genetic investigators have focused on T-cell receptor genes, immunoglobulin genes, angiotensin converting enzyme gene, chemokine genes and others.

From a review of studies performed in different racial and ethnic groups, a reasonable suggestion arises that genetic factors are the major determinant in the racial variations in the epidemiology of the disorder. This assumption is, however, so far limited by lack of studies considering both genetic and environmental factors simultaneously.

Eur Respir J 2000; 16: 768-780.

Sarcoidosis is an immune-mediated multiorgan disorder of unknown origin, characterized by the presence of noncaseating granulomata [1]. The earliest step in the immunological events leading to granuloma formation is the accumulation of T-lymphocytes and mononuclear phagocytes in the affected organs, activated CD45R0+ve T-helper (Th)1-type T-cells being central to this infiltration. Such a phenomenon is up-regulated at sites of inflammation by two mechanisms: the expansion of CD4+ve memory cells, following a redistribution from blood flow, under the influence of several chemokines, and in situ interleukin (IL)-2 mediated proliferation [2-4] In brief, granuloma formation in sarcoidosis seems to be ruled by a Th1-type response of T-cells.

The above mentioned pathway of sarcoidosis, although extremely simplified, is the result of significant advances made in the understanding of the disease's pathogenesis during the past two decades. This feature is shared by many other pulmonary disorders, such as asthma, chronic obstructive pulmonary disease (COPD), idiopathic pulmonary fibrosis (IPF), primary pulmonary hypertension, pulmonary alveolar proteinosis, all conditions in which biochemistry, cell biology, and molecular biology techniques have yielded pathogenesis breakthrough.

These conditions, like sarcoidosis, are common disorders triggered by an intricate combination of environmental (known in some cases, unknown in the others) and genetic (largely undetermined) factors [5]. Under this point of view, they are defined as complex (or polygenic)
*Clinica di Malattie dell'Apparato Respiratorio, IRCCS Policlinico San Matteo, Università di Pavia, and ${ }^{\#}$ Cattedra di Malattie dell'Apparato Respiratorio, Università di Perugia, Italy.

Correspondence: M. Luisetti Laboratorio di Biochimica e Genetica Clinicadi Malattie dell'Apparato Respiratorio IRCCS Policlinico San Matteo Via Taramelli 5 27100 Pavia Italy Fax: 0382502269

Keywords: Angiotensin converting enzyme candidate genes

deoxyribonucleic acid

epidemiology

linkage analysis

major histocompatibility complex

Received: April 102000

Accepted after revision June 152000

Supported by the Italian Ministry of Health, CF project, law 548/93, with a grant given to IRCCS Policlinico San Matteo, Pavia. disorders (or traits), distinguishing them from disorders due to single gene mutations (monogenic or Mendelian disorders, such as $\alpha_{1}$-antitrypsin deficiency or cystic fibrosis). The current challenge concerning complex disorders is the elucidation of genetic mechanisms and the identification of related susceptibility genes [5].

Genetic susceptibility to sarcoidosis is suggested by two robust lines of evidence. These are, racial and, to a lesser extent, ethnic variation in sarcoidosis incidence; and familial clustering of the disease [6]. However, the understanding of the genetic boundaries of this supporting evidence is limited by the fact that the aetiology of sarcoidosis remains unknown. One cannot, therefore, exclude that some racial variation might be attributed to varying environmental risk. In addition, families share not only genes but also their environment. In this framework, genetic studies on sarcoidosis have developed on a less favourable background than other complex disorders, such as COPD or chronic beryllium disease, for which the knowledge of major environmental determinants has allowed, for instance, a better definition of phenotypes [7, 8]. Nevertheless, genetic studies on sarcoidosis have accumulated enough supporting evidence that it is now an established concept that some genetic factors have a role in altering the disease phenotype, i.e. its clinical expression [4]. What remains to be elucidated is how these factors alter the disease phenotype and, maybe more interestingly, whether genetic factors affect susceptibility to sarcoidosis [4]. 
Interactions between environmental and genetic factors in the development of sarcoidosis received little, if any, attention in previous studies. To address this point (among others), a Case Control Etiologic Study of Sarcoidosis (ACCESS) [9] has been sponsored by the National Heart, Lung and Blood Institute (NHLBI). The aim is to enrol 720 newly diagnosed cases of sarcoidosis and compare them with 720 age, sex, and race matched controls in a study that has the potential to test different aetiological hypotheses or, at least, to generate other strong hypotheses [9].

This paper reviews the current knowledge on genetic components of sarcoidosis which led to the rationale for the study design based on genetic and environmental hypotheses, a major priority of the ACCESS study.

\section{Relationship between genetic and environmental factors affecting the epidemiology of sarcoidosis}

Racial and ethnic variations in sarcoidosis epidemiology and presentation

Sarcoidosis occurs worldwide. The disease affects both sexes, but a slight excess of females over males has been reported in many series [1]. People of all ages may be involved, but sarcoidosis is a disorder typically affecting young adults (20-40 yrs), with a second peak in females $>50$ yrs in Japan and Scandinavian regions $[10,11]$.

The disorder is distributed among all races (broad supertypes, as Caucasian) and ethnic groups (split subtypes, as Italians), but with marked variations. Overall prevalence ranges from $\sim 50$ per 100,000 inhabitants (Sweden, Denmark, USA (African-Americans) to $<1$ per 100,000 (Spain, Portugal, Italy, Saudi Arabia, India) [12]. In a population-based study in Rochester, Minnesota, USA, the incidence rates were 5.9 per 100,000 person $\cdot \mathrm{yr}^{-1}$ for males and 6.3 for females [13], whereas an annual all-race incidence rate of 4.8 per 100,000 persons was estimated in a Northwest US population [14]. In a comparative study, the prevalence of sarcoidosis in Finland was 28.2 per 100,00 and 3.7 per 100,000 in Japan (Hokkaido area) [15]. Studies in homogeneous areas have shown marked racial variations. A study among 1,216, 425 recruits entering the US Navy 19581969 showed that sarcoidosis affected African-Americans 10-17 times more frequently than Caucasians [16]. More recently, in the Detroit area, the annual incidence of the disorder was 36.3 per 100,000 among AfricanAmericans, and 11.3 per 100,000 among Caucasians [17]. In New York City, sarcoidosis prevalence was $>50$ per 100,000 among African-Americans, ranged 40-20 among Puerto Ricans/Hispanics, and dropped to 10-20 in Caucasians $[12,18]$.

A solid body of evidence suggests that the sarcoidosis phenotype, i.e. presentation and severity, varies in function of racial and ethnic background. Greater severity in African-Americans and more frequent asymptomatic disease in Caucasians are widely accepted concepts [4]. Caucasians show erythema nodosum more frequently than the Japanese [19], and lesser extrapulmonary spread than African-Americans and Japanese [10], whereas the incidence of cardiac sarcoidosis is higher among the Japanese than among Caucasians and African-Americans [10]. In a comparative study of 107 North Italian and 126
Czech patients with sarcoidosis, ethnic-restricted variations were found: $58 \%$ of the Czechs versus $35 \%$ of the Italians were in roentgenologic stage 1 , whereas $7 \%$ only, were in stage III, versus $23 \%$ of the Italians; the disease lasted longer in the Italians than in the Czechs (39 versus 22 months) [20]. Mortality rates are reported to be similar among races [1]. However, a study of sarcoidosis or its complication mortality in the USA from 1979-1991, showed consistently higher age-adjusted mortality rates among African-Americans than among Caucasians [21].

Taken together, these data support the concept that race and ethnicity influence the prevalence/incidence and pattern of sarcoidosis. The most direct conclusion to be drawn from the above mentioned lines of evidence would be that such variations are attributable to genetic factors. However, epidemiological data might by affected by several weaknesses, such as environmental factors (which may vary by race and, to a lesser extent, ethnicity), inequality of ascertainment methods (which may lead to underestimation or misdiagnosis of the disease) and problems in sarcoidosis coding and death certification.

\section{Environmental factors}

As stated before, the cause(s) of sarcoidosis remain unknown. However, reports of sarcoidosis outbreaks in certain communities, occupational risks, and space-time clustering of the disease open up a concrete possibility that sarcoidosis is triggered by a shared environmental exposure or by a transmissible agent [1]. It is, however, important to start off by saying that this issue remains questionable, not only because of the lack of an unambiguous demonstration of the nature of the putative agent, but also because of the inability to reproduce some studies or serious biases in others [22].

Several lines of evidence suggest the possible role of environmental and/or transmissible factors in the pathogenesis of sarcoidosis. This evidence is summarized in the following statements. 1) Reports of temporal aggregation of sarcoidosis in nonconsanguineous family members [23]. 2) Several records of a work-related risk of sarcoidosis (or "sarcoid-like" lesions) in nurses, firefighters and aluminium or zirconium workers [1]. One paper has recently confirmed the risk for firefighters: a 10-yr surveillance in the New York Fire Department (NYFD) showed a point prevalence of 222 per 100,000 , a higher value than among controls [24]. It is worthy of note that non-White individuals accounted for $6 \%$ of all NYFD firefighters, in contrast to $42 \%$ of controls, thus excluding the above mentioned possible effect of a racial variation. 3) Seasonal occurrences of sarcoidosis have been described in both hemispheres [25]. In addition, a climatic influence on both prevalence and modality of disease presentation in Japan has been reported [26]. 4) Finally, recurrence of sarcoidosis from extrathoracic tissues after lung transplantation and possible transmission of the disease via allogeneic bone marrow transplantation [27] further strengthen the hypothesis of a transmissible agent.

Perhaps the most important investigation in this field is the Isle of Man case-controlled study of 96 patients with sarcoidosis diagnosed 1962-1983 [28, 29]. The high frequency of contacts $(\sim 40 \%)$ among cases, and strong links between cases separated by time intervals of $<10$ yrs and distances $<100 \mathrm{~m}$ (time-space clustering) are 
classically reported as the strongest evidence supporting the hypothesis that a transmissible agent causes sarcoidosis [1]. However, as recently pointed out by RYBICKI et al. [6], the isle of Man study contains circumstantial evidence that genetic factors might have played a role: in fact, there were 9 cases of familial sarcoidosis, but no cases among nonconsanguineous family members. In addition, percentage of cases in subjects of Manx ancestry was higher than expected.

Besides inorganic or organic pollutants, many infectious agents including viruses, Borrelia burgdorferi, Propionibacterium acnes, mycobacteria, and mycoplasma have been suspected to be able to elicit the granulomatous response deserved in sarcoidosis. These issues have been extensively reviewed in previous papers $[3,4]$. However, in spite of intriguing findings, the unsuccessful attempt to isolate any given agent consistently or to create reproducible animal models failed to support the hypothesis that an infectious agent underlies sarcoidosis [4]. Nevertheless, contrasting results obtained in the search for mycobacterial deoxyribonucleic acid (DNA) in sarcoid tissues do not rule out a possible role of these agents, at least in a subset of subjects with sarcoidosis [30]. This concept fits with the oligoclonality of the disease [3]; in other words, an oligoclonal T-cell activation would be elicited by a still elusive "sarcoid agent".

In summary, several reports exist suggesting that environmental factors may elicit sarcoidosis. However, choice of convenient samples of cases, lack of necessary statistical power, and the fact that interactions with genetic factors were never taken into account, may have significantly affected many of these studies [6].

\section{Do environmental factors explain racial and ethnic variations in sarcoidosis epidemiology?}

As stated before, it is likely that genetic background accounts for racial and ethnic variations in the epidemiology of sarcoidosis. However, tough in the absence of an unambiguous demonstration of an environmental and/or transmissible agent, one cannot rule out a priori that environmental factors might account for such variations. As an example, a striking difference was reported between the prevalence rates of sarcoidosis in native Londoners (27 per 100,000) and Irish immigrants living in North London (97 per 100,000) [12]. Interestingly, mass miniature radiography screening in Ireland showed a prevalence of 33 per 100,000 [31], a figure not different from that found in Londoners. Although differences exist in the age selection for screening between the two studies, such a great variation in two ethnically homogeneous populations suggests a role for factor(s) to which Irish immigrants are more susceptible than native Londoners [12]. However, lack of information and/or greater differences in screening methods and socioeconomic context prevent this feature from being confirmed in other parts of the world.

\section{Familial aggregation of sarcoidosis}

Several hundred kindreds with sarcoidosis have been reported worldwide [32] Evidence that sarcoidosis clusters in families, with two or more members affected, is considered the strongest support for a genetic component of the disorder [6]. The first extensive report of this occurrence was published in 1973 by the Research Committee of the British Thoracic and Tuberculosis Association [33], and described 121 subjects distributed among 59 families. Interestingly, this study showed an excess of monozygotic over dizygotic twins concordant for sarcoidosis. A high prevalence of familial sarcoidosis has also been described in Ireland [34], but the overall prevalence of the disease is high in this country. In this Irish study, $9.6 \%$ of index cases were found to have at least one sibling with sarcoidosis. In a comparative study in Finland and Hokkaido, Japan, prevalence of familial sarcoidosis was comparable, being $3.6-4.7 \%$ in Finland and $2.9-4.3 \%$ in Hokkaido [35], in spite of the marked difference of overall prevalence of the disease between the two regions (28.2 versus 3.7 per 100,000 , respectively) [15].

The most informative study in this field was conducted in the Detroit area in southeastern Michigan. In a preliminary investigation the authors evaluated 727 cases which included 91 families containing 210 affected members with 147 relationships [36]. Prevalence of familial sarcoidosis in that study was $13.5 \%$, but the striking result was that familial sarcoidosis was more commonly detected among African-Americans (18.9\%) than Caucasians $(5.2 \%)$. In other words, African-Americans are four times more likely to have an affected family member. This suggests that African-American sarcoid families are probably the best model for identifying a genetic predisposition to the disease.

The pattern of trait inheritance in familial sarcoidosis has been poorly investigated in the past. Headings et al. [37] estimated an inheritability of $60-70 \%$ in 11 AfricanAmerican families assuming a polygenic inheritance, whereas JAMES et al. [38] suggested a recessive gene inheritance. However, both studies were weakened by a number of problems, including limited sample size. To address this point, RYBICKI et al. [39] examined 3,395 siblings and parents of 558 index cases of sarcoidosis (361 African-Americans and 197 Caucasians). They used individual risk probabilities based on age, sex, and race specific disease prevalence to evaluate risk in parents and siblings of sarcoidosis patients. A significant heterogeneity in familial risk of disease was found; high-risk families were more likely to be African-American (OR $=3.24$ ), and to have an offspring or a second-degree relative affected $(\mathrm{OR}=6.21)$. The significant heterogeneity of family risk found means that subsets of disease with different aetiologies, such as those with a greater genetic or a greater environmental component, exist in families. In conclusion, intrarace heterogeneity in familial risk seems to suggest the involvement of a major gene in susceptibility to sarcoidosis [6].

\section{Do environmental factors explain familial clustering of sarcoidosis?}

As is easy to understand, environmental factors could be responsible for familial aggregation of sarcoidosis. However, in this case, the relative risks conferred by putative environmental agents would have to be so high $(>100)$ that previous case-control studies would have detected them [6]. 


\section{Approaches for identifying genes for sarcoidosis}

From the previous paragraphs it is clear that dissection of a complex trait, such as sarcoidosis, resulting from the interaction of a number of genes with a number of environmental factors, and not following a simple Mendelian inheritance pattern, can hardly be performed by the traditional strategies, such as log of the odds (LOD) score linkage analysis, used for simple Mendelian traits. Linkage analysis consists of the localization of a gene responsible for a disease by evidence of cosegregation of a DNA marker with the phenotype of the disease. Reasons for the difficulty in studying complex traits are the lack of: 1) large series of families with multiple affected individuals; and 2) perfect cosegregation of a genetic marker with inheritance of the trait. These considerations are particularly important for sarcoidosis, for which the relative risk $(\mathrm{RR}=$ recurrence risk for a relative of an affected person divided by the risk in the general population) is rather low (ranging 0.3-2) [3, 40].

Other confounding factors are the genetic heterogeneity of the disease, incomplete penetrance of the disease allelle, and presence of false-positives (phenocopies). Generally speaking, the poorer the definition of a phenotype, the lower the power of linkage analysis in mapping the disease [41]. Despite the complexity of the situation, significant advances have been made in discovering and characterizing genes involved in complex traits. Two different strategies are being used: genome scanning and candidate gene analysis.

\section{Genome scanning}

Genome scanning implies the lack of particular candidate genomic regions because of incomplete knowledge of the biochemical basis of the disease. The above mentioned traditional linkage analysis, involving observation of cosegregation and recombination between known DNA markers and unknown trait-influencing alleles in members of large pedigrees cannot easily be applied to sarcoidosis, as before mentioned. Attractive alternatives are the allele-sharing methods, aimed at assessing marker alleles shared at a given locus among pairs of relatives affected [42]. The simplest of these methods is sib pair analysis, in which allele frequency is determined among affected sibs in a family and compared with expected $50 \%$ inheritance by chance. Such a strategy has been successfully applied in the past to the identification of susceptibility loci for essential arterial hypertension and type 1 diabetes mellitus [41]. Sib pair analysis would be the method of choice for linkage analysis in sarcoidosis, rather than the traditional LOD score analysis, because: 1) multiplex sarcoid families usually have no more than 2-3 members affected; and 2) sarcoidosis is a short-lived condition, often resolving spontaneously, and therefore underdiagnosed cases within the family would weaken the statistical power of the LOD score method [40].

\section{Candidate gene analysis}

This strategy is based on the investigation of frequencies of particular gene variants in a population of unrelated affected individuals in comparison with frequencies in a control population of unrelated, unaffected individuals. Of course, this strategy implies the knowledge, at least in part, of the biochemical basis of the disorder, and knowledge about the function of the gene variant (fig. 1). Beside these considerations, important pitfalls linked to case-control studies are the huge numbers of putative candidate genes to be investigated for any given disorder, and, maybe more relevant, the heterogeneity of populations studied, both affected and unaffected. A possible way of circumventing the latter problem is to generate an artificial control population by studying an unaffected control population composed by unaffected family members [40]. This strategy is called affected family-based controls AFBAC [43]. The control group generated in this way is well matched for ethnic ancestry.

In the following paragraphs the evidence so far collected, mostly from case-control association studies, for genetic factors in sarcoidosis is reviewed.

\section{Major histocompatibility complex genes}

Human leukocyte antigen (HLA) genes of the major histocompatibility complex (MHC) map to the short arm of chromosome 6 (fig. 2). Interest in the involvement of these loci in genetic susceptibility to sarcoidosis dates back to the mid 1970s and has resulted in large numbers of studies, first performed at a serological level and more recently with molecular biology techniques. The pathophysiology of sarcoidosis, implying antigen recognition, processing, and presentation to T-cells by antigen presenting cells underlies the rationale for investigating HLA, especially class 11, genes [3]. The role of HLA molecules in disease susceptibility and modulation of clinical manifestations can be summarized as follows: 1) molecular mimicry or antigenic cross-reactivity between

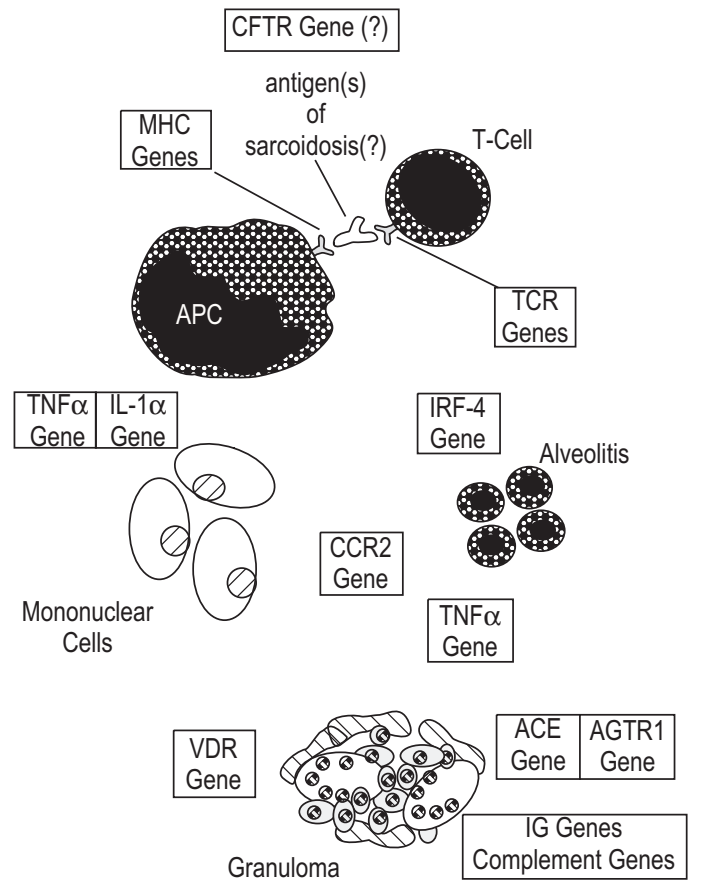

Fig. 1. - Candidate genes for sarcoidosis investigated according to the current concepts in the pathogenesis of the disorder. CFTR: cystic fibrosis transmembrane regulator; APC: antigen presenting cell; TCR: T cell receptor; IRF-4: Interferon Regulaor factor 4; CCR2: C-C Chemokine receptor 2; VDR: Vitamin D receptors; AGTR1: Angiotensin II Type Receptor; Ig: Immunoglobulins. 
Class II region

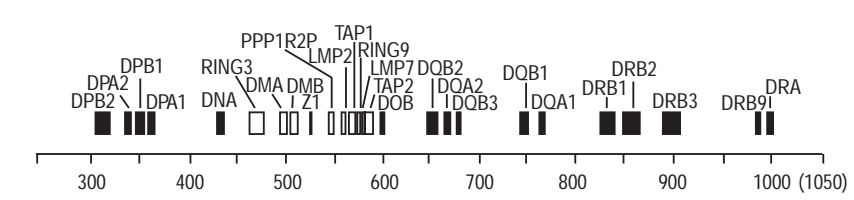

Class III region

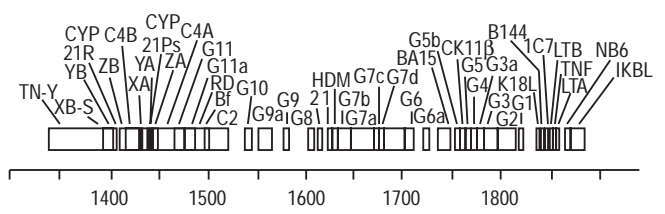

Centromeric

Class I region

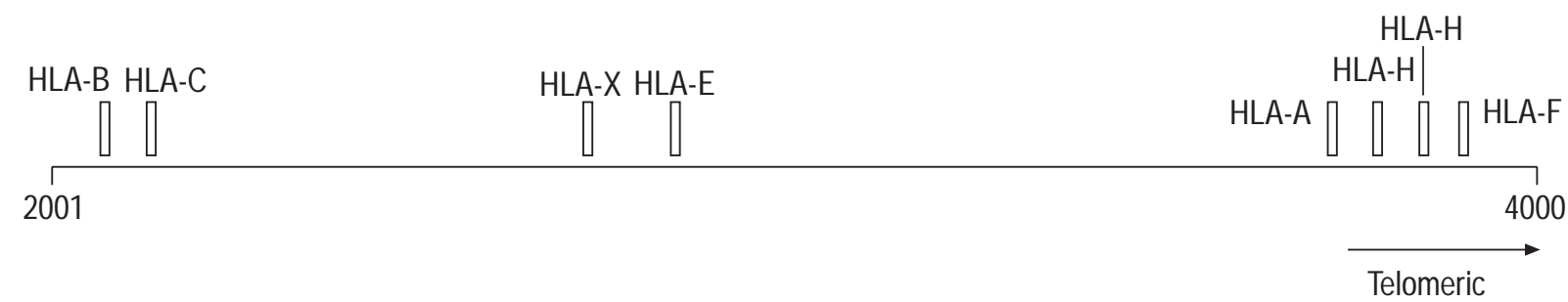

Fig. 2. - Scheme of the major histocompatibility complex (MHC), mapping to short arm of chromosome 6. Class I genes are expressed on the surface of most cell types and they are involved in the presentation of peptides deriving from any given synthesized protein. Class II region contains human leukocyte antigen (HLA)-DR, -DP, and -DQ genes, which are expressed only in antigen presenting cells (APC), and present selected antigens. Also nonHLA genes, such as low-molecular-weight polypeptides (LMP) and transporter associated with antigen processing (TAP), map to the class II region. Class III region is located between class II and class I, and contains (centromeric to telomeric): genes encoding for the complement components (C4, factor B, C2), those encoding for the $70 \mathrm{kD}$ Heat shock proteins (Hsp70), and the tumour necrosis factor (TNF) gene complex.

infectious organisms and HLA sequences, producing an initial tolerance that allows an infectious organism to become invasive e.g. due to antigenic cross-reactivity, individuals carrying the HLA-B27 allelle are unable to mount antibodies towards Klebsiella spp; 2) direct binding of pathogens or antigens to specific HLA molecules; 3) HLA-restricted control of immune response; and 4) aberrant HLA molecule expression in sites of disease activity [20].

\section{Human leukocyte antigen class $I(A, B, C)$ genes and sarcoidosis}

To the authors' knowledge, the first study of HLAsarcoidosis association was performed in 1974 by KUEPPERS et al. in 132 sarcoid patients from what was then West Germany [44]. This study failed to detect any associations between the HLA locus A and the disease. Subsequently, a number of studies in Caucasian sarcoid subjects belonging to different ethnic groups found an association with the HLA-B8 antigen. The RR for the B8 antigen was quite constant: 2.18 in the UK [45], 2.22 in North America [46], and 2.8 in Moravia (Czech Republic) [47]. The last study also reported a $R R=8.5$ for the genotype B8/B13. In the first study in 32 AfricanAmerican sarcoid subjects no associations were found [48]. The first HLA typing in familial sarcoidosis also dates to this pioneering era [49]. In 55 members of 14 families haplotype segregation was similar to the predicted, suggesting against HLA-association. All the above mentioned studies were performed at a serological level, using standard microlymphocytotoxicity methods.
Human leukocyte antigen class I and class II (DR, DP, $D Q)$ genes and sarcoidosis

Besides HLA class I genes, other studies have taken into account DR, DP, and DQ genes (or gene products). With reference to Caucasian subjects, HLA-DR5 was significantly associated with the disease in 73 German patients $(\mathrm{OR}=6.56)$ [50], whereas no associations were found with DR antigens in 107 Italian patients [51]. In the latter study, a positive association with HLA-B8 antigen was confirmed $(\mathrm{RR}=1.91)$. Two Japanese studies have dealt with HLA class I and II (DR, DQ) antigens: a study by KUNIKANE et al. [52] including 53 patients, and one by INA et al. [53] including 114 subjects. Both studies agreed that the frequency of HLA-DRw52 antigen was higher in patients with sarcoidosis than in healthy controls. In addition, the study by INA et al. [53] showed an increased frequency of $\mathrm{A} 1(\mathrm{RR}=8.65), \mathrm{B} 7(\mathrm{RR}=8.52), \mathrm{Bw} 46(\mathrm{RR}=$ 4.14), Cw6 ( $R R=8.52), C x 46(R R=6.45)$, $D R w 8(R R=$ 2.47), and DRw9 ( $R R=1.90)$ antigens; no association with DQ antigens was found. A Danish study of 41 subjects [54] showed a significant association with DRw6 $(\mathrm{RR}=3.2)$, but no association with $\mathrm{DQ}$ or DP antigens.

Subsequently, molecular HLA class II studies were carried out. Such studies lower the frequency of incorrect results associated with serological HLA typing [55]. In 32 Japanese patients with sarcoidosis no restriction fragment length polymorphisms (RFLP) of HLA-DR $\beta$ gene specific for sarcoidosis were found, but in subjects serologically positive for the DRw52 antigen, frequency of restriction fragments was higher than in controls [56]. In a larger sample of Japanese patients, IsHIHARA et al. [57] performed HLA-DRB1, -DRB3, DQA1, and-DQB1 genotyping. Significant associations with sarcoidosis 
were found for the DR52-associated DRB1 alleles [DRB1*11 (RR=5.9), DRB1*12 (RR 2.9), DRB1*14 $(\mathrm{RR}=2.8)], \mathrm{DRB} 1 * 08(\mathrm{RR}=3.5), \mathrm{DRB} 3 * 0101(\mathrm{RR}=3.1)$, DQA $1 * 0501 \quad(\mathrm{RR}=4.6)$, and $\mathrm{DQB} 1 * 0301 \quad(\mathrm{RR}=3.9)$. Interestingly, this study suggests that a glutamate residue in position 71 (Glu71) of the DRB1*1302, and a leucine residue in position $11\left(\mathrm{Leu}^{11}\right)$ of DRB1*0101 are both associated with resistance ( $R R=0.1)$ to sarcoidosis in the Japanese. More recently, in 122 Scandinavian patients with sarcoidosis, DR17(3) was found to be significantly associated with the disease $(\mathrm{p}<0.001$ versus 250 healthy controls) [58]. The DQB $1 * 0201 / 0202$ allele was also associated with sarcoidosis in this study $(\mathrm{p}<0.01)$.

\section{HLA-DPB1 gene and sarcoidosis}

HLA class II DPB1 gene has received particular attention since RICHELDI et al. [59] demonstrated that berylliosis is strongly associated with the HLA class II DPB $1 * 0201$ allele, whereas the DPB1*0401 allele seemed to protect against the disease. Sequence analysis showed that berylliosis susceptibility was linked to the polymorphic sequence coding for a Lys to Glu amino acid change in position 69 of the $\beta$-chain of the HLA-DP gene $\left(\right.$ HLA-DPGlu $\left.{ }^{69}\right)$. It is particularly interesting that beryllium inhalation produces granulomata in the lung which are pathologically indistinguishable from those found in sarcoidosis [8], so that berylliosis is also referred to as "a form of sarcoidosis of known cause". Such homology prompted investigators to search for a possible association between HLA-DPB1 and sarcoidosis. In an early work, frequencies of DPB $1 * 0201$ and DPB $1 * 0401$ alleles were found not to be different between Italian sarcoid patients and controls [60], but this study was compromised by its limited sample size. A similar negative result was more recently reported by MALIARIK et al. [61] in 69 African-American patients with sarcoidosis, in which the frequency of HLA-DPGlu ${ }^{69}$ was only slightly increased over that in controls. The same authors did, however, report a weak association for $\mathrm{Val}^{36}(\mathrm{OR}=2.30)$ and for $\mathrm{Asp}^{55}$ (OR=2.03), suggesting that such residues may contribute to sarcoidosis susceptibility in African-Americans. In contrast, in 41 British subjects with sarcoidosis, LYMPANY et al. [62], although unable to find an association with HLA class II alleles or to confirm the association with the DPB1 position 55, reported that 26/47 sarcoid subjects had DPB $1 *$ Glu ${ }^{69}$ alleles, this being a significantly higher frequency than that in the controls $(\mathrm{p}<0.02)$. Consistent with this finding, SCHÜRmANn et al. [63] in a study of 37 kindreds from 17 German families, described a greater than expected frequency of DPB $1 * 0201$ alleles. However, the finding of LYMPHANY et al. [62] could not be replicated by the same group in a larger series of British patients [64].

\section{Non-human leukocyte antigen class II genes and sarcoidosis}

The class II region of HLA contains non-HLA genes, such as low-molecular-weight polypeptides (LMP) and transporter associated with antigen processing (TAP), encoding components playing a role mainly in a class I restricted presentation pathway $[65,66]$. LMP2 and LMP7 genes encode two subunits of the multicatalytic protea- some involved in digestion of antigenic peptides binding to class I molecules. TAP1 and TAP2 genes are involved in the transport of endogenous peptides prior to assembly of class I molecules. The latter are of some interest in sarcoidosis, not only from a linkage disequilibrium point of view (i.e. the tendency for genes located close to each other on the same chromosome to be inherited together), but also for a possible role of their polymorphisms in the self-tolerance breakdown [64]. Several polymorphic variations of TAP and LMP genes have been extensively investigated in the Japanese [67-69]. From the analysis of the data, the authors concluded that TAP and LMP genes are not primarily involved in genetic susceptibility. The significant decrease in the frequency of TAP $2 * 0201$ allele in sarcoid patients negative for DR5, DR6, and DR8 was explained on the basis of its linkage disequilibrium with the associated allele DR1 [68]. An investigation of genetic polymorphism in intron 6 of the LMP7 gene revealed a high frequency of the $\mathrm{LMP} 7{ }^{*} \mathrm{C}$ allele explained, however, by a secondary association with HLA-DRB1*08 in the DRB1 gene [70].

More recently, FOLEY et al. [64] examined several polymorphisms in the TAP1 and TAP2 genes in 117 British sarcoid patients. The TAP2 Ala ${ }^{565} / \mathrm{Thr}^{565}$ and $\mathrm{Thr}^{665} / \mathrm{Ala}^{665}$ genotypes were significantly less represented in the patient group than in 290 controls $(\mathrm{OR}=0.41$ and 0.54 , respectively). In addition, no association was found between variants of the TAP gene loci and HLADPB1.

\section{Major histocompatibility complex class III genes}

Genes encoding for human complement component $\mathrm{C} 2$, factor B and C4 map in the class III region of the MHC. Factor $\mathrm{B}(\mathrm{BF})$ and $\mathrm{C} 4$ are characterized by extreme polymorphism. In an early work on 59 Italian patients with sarcoidosis, the BF F allele was found to be significantly associated with the disease (29\% versus $19 \%$ of 363 controls, $p=0.013$ ) [71]. This finding was not, however, reproduced in a larger series of patient of the same ethnic group [51].

The tumour necrosis factor (TNF) gene complex is located in the same region, $\sim 260 \mathrm{~kb}$ centromeric to HLA$\mathrm{B}$, and includes TNF $\alpha$ and lymphotoxin $\alpha$ (previously referred to as TNF $\beta$ ) genes. TNF $\alpha$ is considered an important mediator in mononuclear cell recruitment, granuloma formation and in the immunopathogenesis of progressive sarcoid disease $[2,3]$. Two bi-allelic TNF gene complex polymorphisms have been described: Lt $\alpha$ Ncol, in the first intron of the lymphotoxin $\alpha$ gene, and TNF-308, in the promoter region of the TNF $\alpha$ gene. Lt $\alpha$ Ncol $* 1$ and TNF-308*2 alleles are associated with higher levels of TNF production. Neither polymorphism was significantly associated with sarcoidosis as a whole in 101 German sarcoid patients [72]. The same lack of association for the TNF-308 polymorphism was recorded in a limited sample of Italian patients with sarcoidosis [73]. In a Japanese study of 75 patients with sarcoidosis, the Lt $\alpha$ Ncol polymorphism was examined, in addition to polymorphisms in three genes encoding the 70,000 D heat shock proteins (HSP70), mapping to the $\mathrm{MCH}$ region, between the $\mathrm{C} 2$ and TNF loci (fig. 2). Neither LtaNcol nor HSP70-related genes were found to be associated with the disease [74]. The overrepresentation 
of the LtoNcol*1 allele was explained by linkage disequilibrium with HLA-DR5, DR6, and DR8 antigen groups.

\section{Major histocompatibility complex genes and hetero-} geneity of the disease

It is well recognized that sarcoidosis is a heterogeneous disorder, with its clinical course, extrapulmonary involvement, and variable outcome [1]. The relationship between MHC products/genes and sarcoidosis phenotypic variants of sarcoidosis is probably the genetic aspect of the disease in which investigators have had most success. The concept that immunogenetic background accounts, at least partly, for the clinical heterogeneity of sarcoidosis has been verified by different investigators in different racial and ethnic groups of affected individuals. Some of the relevant results obtained in this field are summarized, for ease of comprehension, in table 1. Correspondence analysis, a statistical exploratory technique for understanding multivariate data, has been successfully applied to the visual representation in a multidimensional space of the interaction between HLA antigens and clinical characteristics of sarcoidosis, thus generating a "map" that may help clinicians to interpret immunogenetic data [20] (fig. 3).

\section{Major histocompatibility complex comparative studies in multiple racial or ethnic groups}

Taking into account the racial and ethnic variations in sarcoidosis epidemiology and presentation discussed above, probably the most informative kind of approach is that of MHC comparative studies in multiple well defined racial or ethnic groups. First of all, populations with mixed genetic background may affect the linkage. Studying clearly racially or ethnically defined populations would explain some negative results obtained in mixed populations. Moreover, the chance of finding shared HLA features passing over ethnic and, even better, racial boundaries, would highlight the importance of $\mathrm{MHC}$ genes in sarcoidosis susceptibility. Unfortunately, only a few studies have used this approach. In an early work, HLA class I and DR typing was performed in 34 white sarcoid patients of British descent and in 28 Black West
Indian patients of African descent [80]. English patients were characterized by a significant increase of $\mathrm{Cw} 7$ (RR 34.2) and by the association of the haplotype $\mathrm{B} 8 / \mathrm{Cw} 7 /$ DR3 with good prognosis; neither feature was shared by the West Indian population. In the paper by MARTINETTI et al. [20], dealing with HLA class I and II frequencies in two ethnic groups, Italians and Czechs, some ethnicrestricted findings were shown: in the Czech sarcoid population HLA-B13 and -B22 were related with male sex, early onset, extrapulmonary spread, and relapses, whereas in the Italians these two antigens were related only to disease spread. Finally, a study by FolEY et al. [64] on TAP1 and TAP2 gene polymorphisms in 117 British and 87 Polish sarcoid patients demonstrated a different frequency of the TAP2 $\mathrm{Val}^{379}$ variant (less represented in the Polish patients; $\mathrm{p}<0.02$ versus the British) and of the TAP2 Thr ${ }^{565}$ variant (more represented in the Polish patients; $\mathrm{p}=0.01$ ).

\section{T-cell antigen receptor genes}

As previously stated, T-cells are central to granuloma formation in sarcoidosis. These cells recognize antigens by means of their TCRs, which are characterized by a tremendous diversity due to rearrangement of variable, diversity, and junctional segments of $\alpha / \beta$ or $\gamma / \delta$ T-cell antigen receptor (TCR) chains [3, 81]. Segments are encoded by multiple genes. Several studies investigating the molecular structure of the (TRC) genes have provided evidence that sites of inflammation in sarcoidosis are characterized by selective expansion of oligoclonal populations of T-cells, thus suggesting that the immune response is elicited by "sarcoid" antigen(s) [3, 81].

A few studies have dealt with TRC genes from a genetic point of view. The results of a case-control study screening for associations between marker alleles in candidate regions and sarcoidosis in African-American subjects were very recently reported [82]. The candidate regions were TCR genes on chromosomes 7 and 14, IL-1 $\alpha$, IL-2 receptor $\beta$, interferon regulatory factor 1 and 4 , all involved in the T-cell mediated immune response. The authors found no evidence of associations for TCR gene markers, but did find significant associations for two

Table 1. - Relationship between major histocompatibility complex (MHC) and phenotypic variants of sarcoidosis

\begin{tabular}{|c|c|c|c|c|}
\hline MHC antigen/gene & Clinical expression & Subjects & Author & {$[\operatorname{Ref}]$} \\
\hline HLA-B8 & Spontaneous resolution (RR 3.74) & 87 British patients & SMITH & [75] \\
\hline HLA-B8/DR3 & Acute onset/arthritis Good outcome & 19 Swedish patients & HEDFORS & [76] \\
\hline HLA-DR5J & Poor outcome & 58 Japanese patients & $\mathrm{ABE}$ & [77] \\
\hline HLA-A1, B8, B27, DR3 & Stage I & $\begin{array}{l}233 \text { patients, } 126 \text { Czechs } \\
\text { and } 107 \text { Italians }\end{array}$ & MARTINETti & [20] \\
\hline HLA-B12, DR4 & Stage III & & & \\
\hline HLA-DR3 & Good outcome & & & \\
\hline HLA-B13, B35 & Early onset & & & \\
\hline HLA-A30, B8, DR3, DR4 & Late onset & & & \\
\hline HLA-DR3, DR5, DR6, DR8 & $\begin{array}{l}\text { Early onset, lack of opthalmic } \\
\text { involvement }\end{array}$ & 77 Japanese patients & ISHIHARA & [78] \\
\hline HLA-DR17(3) & Good prognosis & 122 Scandinavian patients & BERLIN & [58] \\
\hline HLA-DR14(6), DR15(2) & Chronic disease & & & \\
\hline \multirow{2}{*}{ TNF-308*2 allele } & Löfgren's syndrome & 101 German patients & SEITZER & [72] \\
\hline & Cardiac localization & 26 Japanese patients & TAKASHIGE & [79] \\
\hline
\end{tabular}

HLA: Human leukocyte antigen; TNF: tumour necrosis factor. 


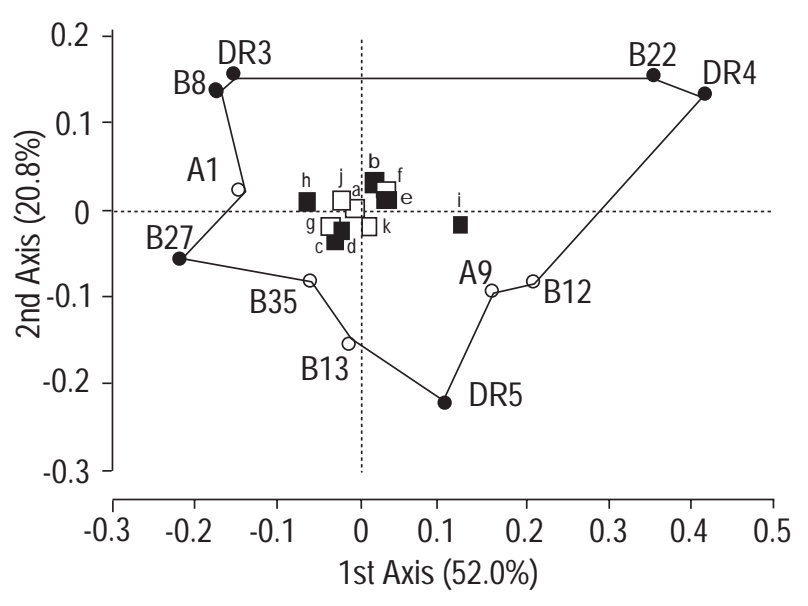

Fig. 3. - Correspondence analysis of clinical and immunogenetic data of 126 Czech and 107 Italian sarcoid patients. The map was built from a matrix in which rows represented clinical parameters $\square,(\boldsymbol{\square}$; a: total patients; b: males; c: females; d: onset $\leq 41$ yrs; e: onset $>41$ yrs; f: presence of extrapulmonary location, yes; g: absence of extrapulmonary location, no; h: stage I; i: stage III; j: resolution; k: relapsed), and columns represented human leukocyte antigens $(\mathrm{O}, \mathbf{0}$; HLAs) selected by means of classic statistical methods. Total variability was analysed, and delineated by vertex points depicting HLA. The distance between points or clinical characteristics is proportional to their degree of diversity, respectively. For instance, point $h$ (corresponding to stage 1) in the upper left section is related to the allelic combination A1, B8 and DR3, whereas point $\mathrm{i}$ (stage III) in the lower right section is more linked to the alleles A9, B12 and DR5. O, $\mathbf{\square}$ : most important alleles/clinical characteristics (see text). (Reproduced with permission from [20].)

cytokines, IL-1 and interferon regulator factor-4. These findings will be discussed later.

\section{T-cell receptor and human leukocyte antigen}

Antigens recognized by TCRs are embedded in a specific cleft of the MHC molecules located on the surface of antigen-presenting cells. A correlation has been found in Scandinavian sarcoid patients between HLA-DR17 (DRB1*0301; a split of DR3), and accumulation in the lung of CD4 +ve T-cells expressing a particular TCR variable gene segment, $\mathrm{V} \alpha 2.3$ (also referred to as AV2S3) [83]. Evidence that these cells show identical $\alpha$-chain amino acid sequences, but different nucleotide sequences suggests a possible selection of T-cell clones to interact with specific sarcoid antigen(s) [84]. The same group investigated a series of 16 HLA-typed Japanese patients with sarcoidosis [85]. It is well known that DR3 is a rare antigen in the Japanese, and none of the patients expressed it. Interestingly, this feature was coupled with lack of $\mathrm{V} \alpha 2.3+v e \mathrm{CD} 4+v e$ lung T-cells. Very recently, in their continuing interest in this field, the same authors further analysed the TCR/HLA interaction with respect to clinical features. In a group of 51 DRB $1 * 0301 / D R B 3 *$ 0101- positive Scandinavian sarcoid patients, there was a significantly higher count of $\mathrm{V} \alpha 2.3+v e \mathrm{CD} 4+v e$ lung Tcells in the subset of patients with shorter duration of disease $(<2$ yrs) [86].

Such evidence, coupled with previously reported findings of a relationship between HLA-DR3 and favourable outcome of sarcoidosis [20,58], opens up intriguing speculations about the nature of the "sarcoidosis antigen(s)". As suggested by GRUNEwald et al. [87], since
HLA-DR3 is a highly specialized mycobacterial antigen presenting molecule, one cannot exclude that mycobacteria might be involved in the pathogenesis of sarcoidosis in a subset of patients characterized by good outcome.

\section{Immunoglobulin genes}

Immunoglobulin (Ig) probably plays an ancillary role, if any, in the pathogenesis of sarcoidosis. However, immunoglobulin levels are often raised in sarcoidosis, with increased antibody titres against a variety of antigens [88]. Specific markers of the constant region of the IgG heavy (IGHG) and Kappa light chains are encoded by a gene cluster (GM and $\mathrm{KM}$ ), located on the long arm of chromosome 14 and 2, respectively. In spite of the limited role of Ig in the pathogenesis of sarcoidosis, GM and KM allotypes, together with $\mathrm{MCH}$ and TCR genes, account for the most informative triad of genes involved in immune-related diseases, therefore they are worthy of investigation in sarcoidosis too. In an early work, the Ig marker G3m[5] was found in 94/95 African-Americans sarcoid subjects investigated [89]. However, the same marker was found in 88/97 controls, and no information was provided about the Ig specificities tested. More recently, GM and KM serotyping was performed in 107 Italian patients with sarcoidosis [90]. In this study the $\mathrm{GM}\left(35^{*}\right)$ phenotype has a "protective" effect $(\mathrm{OR}=$ $0.15)$. In addition, $\operatorname{GM}\left(3235^{*}\right)$ was less represented in patients with stage II and III, when compared to stage I disease.

\section{GM/KM and human leukocyte antigen interaction}

In the same study, since all patients had been characterized for HLA class I,II, and III markers, the epistasis between GM/KM and HLA was investigated [90]. Epistasis, also referred to as gene interaction, is a mechanism by which a certain genotype confers susceptibility or resistance to a degree dictated by the presence of other genotypes and reflects interactive effects of mutations, genotypes and/or their biological products. In this framework, only a few patients carrying the combination $\mathrm{GM}(3$ $\left.235^{*}\right) / \mathrm{Bf} \mathrm{S}$ had stage II disease, i.e. this combination has a "protective" effect against this stage, providing evidence for the first time of an interaction between GM/KM and HLA class III genes in a disease. The already discussed correspondence analysis was applied to this investigation: two distinct major clusters were found. HLA-DR4, C4BQ0, GM (1,3,17 $\left.235^{*}, 21,28\right)$, Bf F was associated with stage II disease, whereas HLA-DR3, C4AQ0, KM(1), GM(3 $\left.235^{*}\right)$ was associated with stage I.

\section{Angiotensin converting enzyme gene}

Angiotensin converting enzyme (ACE) is a metallopeptidase (EC 3.4.15.1) secreted by epithelioid cells. Approximately $50-60 \%$ of patients with sarcoidosis have increased serum levels of ACE, so that its assay is probably the most widely used laboratory test for sarcoidosis [91]. Increased levels of ACE have even been described in other granulomatous and interstitial lung disorders, although with a lower frequency. Since ACE levels tend 
to be higher in patients with stage II and III disease, it was postulated that ACE levels reflect the whole body granuloma mass.

Interestingly, two families, one in Japan [92] and the other in Italy a few years later [93], were described, in which extremely high ACE levels clustered in several family members. The condition affected four members of the Japanese family and five members of the Italian family. Three members of the Japanese family and two of the Italian family were completely healthy, and none of the affected members had abnormal blood pressure. The hyper-ACE-aemia seemed to have been inherited as an autosomal dominant trait (fig. 4). These observations led to a concept of a possible genetic control of ACE levels. In 1990 it was demonstrated that the deletion (D) or the insertion (I) of a $250 \mathrm{bp}$-DNA fragment in intron 16 of the ACE gene accounts for three ACE genotypes, and for $47 \%$ of total phenotypic variance in ACE levels: DD genotype is related to the highest levels, II to the lowest ones, and ID to intermediate levels [94].

Since there is a strong rationale for studying the ACE gene polymorphism in sarcoidosis, in the last 5 yrs a significant amount of data has been accumulated in different racial and ethnic groups, so that there is a satisfactory worldwide picture of ACE gene involvement in sarcoidosis. Probably this polymorphism is the best characterized in sarcoidosis (table 2). 1) Genotype distribution is not different between patients with sarcoidosis and controls in the Caucasians groups studied: Italians [95], Americans [96], and Finnish [97]; 2) Contrasting results were achieved in the Japanese: no association was found in a large series of subjects from central Japan [98], whereas an early report found an excess of ID or DD genotypes among females patients (OR 2.18)[99]: 3) In marked contrast, the DD genotype was a significant risk factor for African-American sarcoid patients (OR 3.17), especially in those with a family history of the disorder [96]. 4) No correlation was found between ACE genotype and sarcoidosis parameters, such as chest radiograph stage, extrapulmonary involvement, and progression in Italian and Japanese patients, whereas a modest correlation was found between the II genotype and radiographic progression among the African-American patients [96]. By contrast, the DD genotype seems to be related to a poor prognosis in Finnish patients [97]. 5) In Japanese

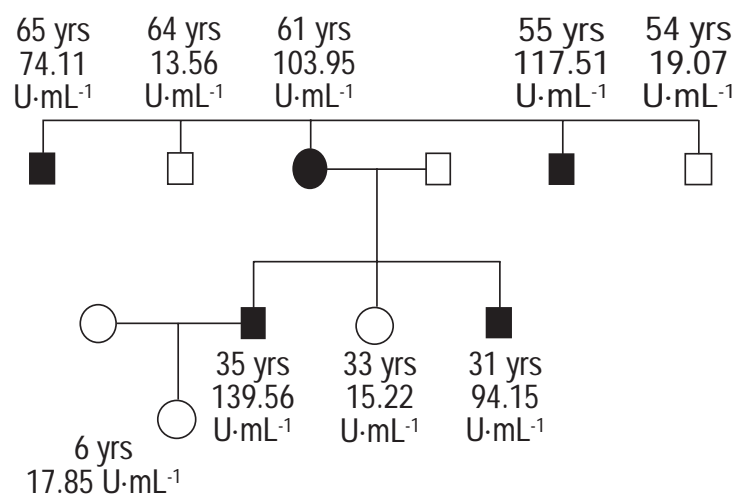

Fig. 4. - Genealogical tree of the Italian hyper-ACE-aemic family. Age and serum ACE values are reported. Closed symbols: subjects with elevated ACE levels; open symbols: subjects with normal ACE levels; $\square$ : males; $\bigcirc$ : females. Reprinted with permission from [93]. sarcoid patients it has been shown that cough and bronchial hyperresponsiveness are significantly related to the ACE II genotype [100]. This is explained on the basis that lower circulating ACE levels inactivate less bradykinin and tachykinins. 6) Finally, nearly all studies agree that the ACE polymorphism accounts for the variability in the serum ACE levels in sarcoidosis too, thus suggesting that new normal ranges should be provided for each genotype [98]. The Italian study, however, hypothesized that chest radiograph stage and ACE genotype act independently of each other in determining ACE levels [95].

In a recent paper, ТАКЕмото et al. [101] showed that the AGTR1 allele c of the polymorphism in an untranslated region of the angiotensin II type I receptor is associated with higher levels of ACE in sarcoidosis, thus suggesting an independent regulatory factor from allele D for ACE elevation in sarcoidosis.

\section{Chemokine/mediator genes}

In spite of the huge amount of information accumulated over the last 20 yrs on the role of chemokines in the pathogenesis of sarcoidosis, these mediators have received only limited attention from a genetic point of view. To the authors' knowledge, only two papers, both published in 1999, have been produced on this matter. In their report on six unlinked candidate regions screened by polymorphic markers, RYBICKI et al. [83] found a significant association with the IL- $1 \alpha$ marker on $2 \mathrm{q} 13$ and with the F13A marker on $6 \mathrm{p} 23-25$. Individuals with both IL-1 $\alpha^{*} 137$ and F13A*188 alleles have a six-fold increased risk of sarcoidosis $(\mathrm{OR}=6.19)$, and this risk is even higher if the analysis is restricted to subjects with a family history of sarcoidosis $(\mathrm{OR}=15.38)$. Both genes code for mediators relevant to the pathogenesis of the disorder: the role of IL- $1 \alpha$ in induction and maintenance of granuloma is well recognized $[2,3]$, whereas the F13A marker is located close to the interferon regulatory factor protein (IRF-4) gene coding for a recently discovered member of the IRF family of transcription factors, which putatively acts as an important mediator in sarcoid-granuloma formation by attracting T-cells.

Monocyte chemotactic protein-1 (MCP-1) is an important chemotactic factor for inflammatory cells in sarcoidosis [102]. C-C chemokine receptor 2 (CCR2) is a receptor for $\mathrm{MCP}-1$, other related chemokines, and human immunodeficiency virus (HIV)-1 infection. A polymorphism in the gene has been described in which the variant $64 \mathrm{Val} \longrightarrow$ lle is associated with delayed progression to acquired immunodeficiency syndrome (AIDS) [103]. The same polymorphism was found to be less frequent in 100 Japanese patients with sarcoidosis than in 122 controls $(\mathrm{OR}=0.369)$ [104]. This would suggest that the variant CCR2-641 protects against developing sarcoidosis.

\section{Blau syndrome and Chrohn's disease genes}

These genes have been recently mapped on chromosome 16. Blau syndrome is a multisystem granulomatous disorder, presenting with iridocyclitis, posterior uveitis, skin localizations, arthritis, and camptodactily; it resembles childhood sarcoidosis [105, 106]. In addition, there are some reports of the coexistence of Crohn's disease and 
Table 2. - Allele and genotype frequencies of angiotensin converting enzyme (ACE) gene intron 16 polymorphism in different racial and ethnic groups

\begin{tabular}{|c|c|c|c|c|c|c|c|c|}
\hline \multirow{2}{*}{ Race-ethnicity } & \multirow{2}{*}{$\begin{array}{c}\text { Subjects } \\
\mathrm{n}\end{array}$} & \multicolumn{2}{|c|}{ Allele frequencies } & \multicolumn{3}{|c|}{ Genotype \% } & \multirow{2}{*}{ P-value } & \multirow{2}{*}{ [Ref] } \\
\hline & & I & $\mathrm{D}$ & II & ID & DD & & \\
\hline Italian/Caucasians & p 61 c 80 & 0.3610 .400 & 0.6390 .600 & 16.412 .5 & 39.355 & 44.332 .5 & ns & [95] \\
\hline American/Caucasians & p 60 с 48 & 0.4830 .416 & 0.5170 .584 & 21.714 .6 & 53.354 .2 & 25.031 .3 & ns & [96] \\
\hline Finnish/Caucasians & p 59 с 70 & 0.4200 .490 & 0.5800 .510 & 1524 & 5449 & 3127 & ns & [97] \\
\hline African-Americans & p 183 c 111 & 0.4300 .558 & 0.5700 .442 & 17.526 .1 & 51.959 .4 & 30.614 .4 & 0.005 & [96] \\
\hline Japanese & p 207 c 314 & 0.6160 .654 & 0.3840 .346 & 37.243 .3 & 48.844 .3 & 1412.4 & ns & [98] \\
\hline Japanese & p 103 c 341 & 0.6100 .680 & 0.3900 .330 & 3546 & 5140 & 1414 & 0.05 & [99] \\
\hline
\end{tabular}

sarcoidosis in different members of the same family [107-109]. The region of chromosome 16 linked to Blau syndrome and Crohn's disease is therefore, a good candidate region for sarcoidosis too. In $35 \mathrm{sib}$ pairs of their series of African-American sarcoidosis patients, RYBICKI et al. [110] were unable to find evidence for linkage of sarcoidosis to the locus, although the effect of a dominant gene with $\mathrm{RR}<5$ or a recessive gene with $\mathrm{RR}$ $<3$ cannot be excluded. However, there are preliminary results from gene scanning performed in 63 German families (on a total of 147 affected and 95 unaffected subjects) showing possible linkage [111].

\section{Miscellanea}

\section{Vitamin D receptor gene}

1,25-Dihydroxy-vitamin D3 $\left(1,25(\mathrm{OH})_{2} \mathrm{D}_{3}\right)$ is one of many sarcoid granuloma products. It has been postulated that its high levels are in part responsible for the increased bone resorption often described during the disorder [112]. In addition, $\left(1,25(\mathrm{OH})_{2} \mathrm{D}_{3}\right)$ has modulating effects on several immune reactions. $\left(1,25(\mathrm{OH})_{2} \mathrm{D}_{3}\right)$ binds to nuclear vitamin $\mathrm{D}$ receptors (VDR), encoded by a gene mapping to chromosome 12. A biallelic polymorphism in intron 8 , accounts for three genotypes, bb, bB, and $\mathrm{BB}$; the bb genotype is related to reduced VDR messenger ribonucleic acid (mRNA) expression. Investigation of this polymorphism in 101 Japanese sarcoid patients revealed that, in comparison to frequencies in 105 healthy controls, there was an excess of both bB genotype $(p=0.0196)$ and $B$ allele $(p=0.0126)$ [113]. However, allele $\mathrm{B}$ was not related to chest radiograph stage of the disease nor to extrapulmonary spread of the disease.

\section{Cystic fibrosis transmembrane conductance regulator gene}

At the present state of the knowledge of the biochemical basis of sarcoidosis, there is no apparent rationale linking the cystic fibrosis gene to the disorder. And yet, the serendipitous finding, during gene screening in different respiratory diseases, that $5 / 8$ sarcoid patients had at least one CFTR mutation [114] raised the possibility of such a relationship, which was subsequently confirmed in a second, larger series of patients in a case-control study [115]. Putting together both studies, 13 out of 34 sarcoid patients show at least one CFTR mutation $(\mathrm{OR}=5.5)$. This relationship is awaiting further confirmation in other series of patients and, more importantly, an explanation: does a modified CFTR protein facilitate entry of an infectious agent into the airways and trigger an immune mediated response?

\section{Concluding thoughts}

The evidence accumulated during the last two decades supporting the concept that genetic factors play a role in the pathogenesis of sarcoidosis has been examined. Based on the information so far collected, it seems possible to state that a general consensus on a couple of items has been achieved: firstly, MHC genes are involved in the phenotypic modifications of sarcoidosis. Secondly, there is a strong suggestion that genetic factors are the major determinants in the racial variations in the epidemiology of the disorder. The latter assumption is however limited by lack of studies considering both genetic and environmental factors simultaneously.

Conversely, the search for susceptibility genes for sarcoidosis is still in its infancy. Only a few candidate genes have been examined extensively, and the associations found are rather weak, from a general point of view. Several studies have found an association with HLA A1, B8, DR3 in Caucasians, suggesting at least an autoimmune component in sarcoidosis, but the association is weakened by the comparison with other disorders [116].

Over the years investigators have created large DNA banks from sarcoid subjects, on which new candidate genes can be easily and quickly tested. However, to strengthen the results, it would be advisable to develop common tools to define the phenotypic variations of the disorder. An example in the assessment of organ involvement was recently reported by the ACCESS Research Group [117].

Two large series of familial sarcoidosis samples have been established, one of African-Americans in the USA, and one of Caucasians in Germany. Whole genome scanning in these samples, and comparative results, will provide a unique opportunity to verify the existence of a locus (or loci) strongly linked to sarcoidosis, and to verify racial and phenotypic variations at a molecular level.

Acknowledgements. The authors thank M. Martinetti for useful discussion. The linguistic assistance of R Stenner is gratefully acknowledged.

\section{References}

1. Newman LS, Rose CS, Maier LA. Sarcoidosis. $N$ Engl J Med 1997; 336: 1224-1234.

2. Semenzato G, Agostini C. Immunologic events in the development of interstitial lung disease: the paradigm of sarcoidosis. In: Schwarz M, King E, eds. Interstitial Lung 
Disease. Hamilton, BC Decker Inc Publ. 1995; pp. 229 250.

3. Müller-Quernheim J. Sarcoidosis: immunopathogenetic concepts and their clinical application. Eur Respir J 1998; 12: 716-738.

4. Hunninghake GW, Costabel U, Ando M, et al. ATS/ERS/ WASOG statement on sarcoidosis. Sarcoidosis Vasc Diffuse Lung Dis 1999; 16: 149-173.

5. Mossman BT, Mason R, McDonald JA, Gail DB. NHLBI Workshop Summary. Advances in molecular genetics, transgenic models, and gene therapy for the study of pulmonary diseases. Am J Respir Crit Care Med 1995; 151: 2065-2069.

6. Rybicki BA, Maliarik MJ, Major M, Popovich J Jr, Iannuzzi MC. Genetics of sarcoidosis. Clin Chest Med 1997; 18: 707-717.

7. Sandford AJ, Weir TD, Paré PD. Genetic risk factors for chronic obstructive pulmonary disease. Eur Respir $J$ 1997; 10: 1380-1391.

8. Saltini C, Amicosante M, Franchi A, Lombardi G, Richeldi L. Immunogenetic basis of environmental lung disease: lessons from the berylliosis model. Eur Respir $J$ 1998; 12: 1463-1475.

9. ACCESS Research Group. Design of A Case Control Etiologic Study of Sarcoidosis (ACCESS). J Clin Epidemiol 1999; 12: 1173-1186.

10. Iwai K, Sekiguti M, Hosoda Y, et al. Racial differences in cardiac sarcoidosis incidence observed at autopsy. Sarcoidosis 1994; 11: 26-31.

11. Milman N, Selroos O. Pulmonary sarcoidosis in the Nordic countries 1950-1982. Epidemiology and clinical picture. Sarcoidosis 1990; 7: 50-57.

12. James DG. Epidemiology of sarcoidosis. Sarcoidosis 1992; 9: 79-87.

13. Henke Ce, Henke G, Elveback LR, Beard CM, Ballard DJ, Kurland RT. The epidemiology of sarcoidosis in Rochester. Minnesota: a population based study of incidence and survival. Am J Epidemiol 1986; 123: 840-845.

14. Reich JM, Johnson RE. Incidence of clinically identified sarcoidosis in a Northwest United States population. Sarcoidosis Vasc Diffuse Lung Dis 1996; 13: 173-177.

15. Pietinalho A, Hiraga Y, Hosoda Y, Löfroos A-B, Yamaguchi M, Selroos O. The frequency of sarcoidosis in Finland and Hokkaido, Japan. A comparative epidemiological study. Sarcoidosis 1995; 12: 61-67.

16. Sartwell PE, Edwards LB. Epidemiology of sarcoidosis in the US Navy. Am J Epidemiol 1974; 99: 250-257.

17. Rybicki BA, Major M, Popovich J Jr, Maliarik MJ, Iannuzzi MC. Racial differences in sarcoidosis incidence: a 5 year study in a health maintenance organization. $\mathrm{Am} \mathrm{J}$ Epidemiol 1997; 145: 234-241.

18. Teirstein AS, Siltzbach LE, Berger H. Patterns of sarcoidosis in three population groups in New York City. Ann N Y Acad Sci 1976; 278: 271-276.

19. Pietinalho A, Ohmichi M, Hiraga Y, Löfroos A-B, Selroos O. The mode of presentation of sarcoidosis in Finland and Hokkaoido, Japan. A comparative analysis of 571 Finnish and 686 Japanese patients. Sarcoidosis Vasc Diffuse Lung Dis 1996; 13: 159-166.

20. Martinetti M, Tinelli C, Kolek V, et al. "The sarcoidosis map": a joint survey of clinical and immunogenetic findings in two European Countries. Am J Respir Crit Care Med 1995; 152: 557-564.

21. Gideon NM, Mannino DM. Sarcoidosis mortality in the United States, 1979-1991: an analysis of multiple-cause mortality data. Am J Med 1996; 100: 423-427.

22. Rybicki BA, Maliarik MJ, Major M, Popovich J Jr,
Iannuzzi MC. Epidemiology, demographics, and genetics of sarcoidosis. Sem Respir Infect 1998; 13: 166-173.

23. Edmondstone WM, Wilson AG. Temporal clustering of familial sarcoidosis in nonconsanguineous relatives. $\mathrm{Br} J$ Dis Chest 1984; 78: 184-186.

24. Prezant DJ, Dhala A, Goldstein A, et al. The incidence, prevalence, and severity of sarcoidosis in New York City Firefighters. Chest 1999; 116: 1183-1193.

25. Wilsher ML. Seasonal clustering of sarcoidosis presenting with erythema nodosum. Eur Respir J 1998; 12: 1197-1199.

26. Yamaguchi M, Hosoda Y, Sasaki R, Aoki K. Epidemiological study on sarcoidosis in Japan. Recent trends in incidence and prevalence rates and changes in epidemiological features. Sarcoidosis 1989; 6: 138-146.

27. Padilla ML, Schilero GJ, Teirstein AS. Sarcoidosis and transplantation. Sarcoidosis Vasc Diffuse Lung Dis 1997; 16: 93-100.

28. Parkes SA, de Baker SB, Bourdillon RE, Murray CRH, Rakshit M. Epidemiology of sarcoidosis in the Isle of Man - 1: A case controlled study. Thorax 1987; 42: 420426.

29. Hills SE, Parkes SA, de Baker SB. Epidemiology of sarcoidosis in the Isle of Man 2: Evidence for space-time clustering. Thorax 1987; 42: 427-430.

30. Mangiapan G, Hance AJ. Mycobacteria and sarcoidosis: an overview and summary of recent molecular biological data. Sarcoidosis 1995; 12: 20-37.

31. Logan J. Prevalence of sarcoidosis in the Irish Republic. Acta Med Scand 1964; 425: 126.

32. James DG, Hosoda Y. Epidemiology. In: James DJ, ed. Sarcoidosis and other granulomatous disorders. New York, Marcel Dekker Inc. 1994; pp. 729-744.

33. British Thoracic and Tuberculosis Association. Familial associations in sarcoidosis. Tubercle 1973; 54: 87-98.

34. Brennan NJ, Crean P, Long JP, Fitzgerald MX. High prevalence of familial sarcoidosis in an Irish population. Thorax 1984; 39: 14-18.

35. Pietinalho A, Ohmichi M, Hirasawa M, Hiraga Y, Löfroos A-B, Selroos O. Familial sarcoidosis in Finland and Hokkaido, Japan- a comparative study. Respir Med 1999; 93: 408-412.

36. Harrington DW, Major M, Rybicki B, Popovich J, Maliarik M, Iannuzzi MC. Familial sarcoidosis: analysis of 91 families. Sarcoidosis 1994; 11: Suppl. 1, 240243.

37. Headings VE, Weston D, Young RC Jr, Hackney RL Jr. Familial sarcoidosis with multiple occurrences in eleven families: a possible mechanism of inheritance. Ann NY Acad Sci 1976; 278: 377-385.

38. James DG, Neville E, Piyasena KH, Walker AN, Hamlyn AN. Possible genetic influences in familial sarcoidosis. Postgrad Med J 1974; 50: 664-670.

39. Rybicki B, Harrington D, Major M, et al. Heterogeneity of familial risk in sarcoidosis. Genet Epidemiol 1996; 13: 23-33.

40. Iannuzi MC. Genetics of sarcoidosis. Monaldi Arch Chest Dis 1998; 53: 609-613.

41. Marian AJ. Molecular approaches for screening of genetic diseases. Chest 1995; 108: 255-265.

42. Schork NJ. Genetics of complex diseases. Approaches, problems, and solutions. Am J Respir Crit Care Med 1997; 156: S103-S109.

43. Thomson G. Mapping disease genes: family-based associations studies. Am J Hum Genet 1995; 57: 487-498.

44. Kueppers F, Mueller-Eckardt C, Heinrich D, Schwab B, 
Brackertz D. HLA antigens of patients with sarcoidosis. Tissue Antigens 1974; 4: 56-58.

45. Brewerton DA, Cockburn C, James DCO, James DC, Neville E. HLA antigens in sarcoidosis. Clin Exp Immunol 1997; 27: 227-229.

46. Olenchock SA, Hise E, Marx J Jr. HLA-B8 in sarcoidosis. Ann Allergy 1981; 47: 151-153.

47. Lenhart K, Kolek V, Bàrtova A. HLA antigens associated with sarcoidosis. Dis Markers 1990; 8: 23-29.

48. Eisenberg H, Terasaki PI, Sharma OP, Mickey MR Jr. HLA association studies in black sarcoidosis patients. Tissue Antigens 1978; 11: 484-486.

49. Turton CWG, Turner-Warwick M, Morris L, Lawler SD. HLA in familial sarcoidosis. In: Jones Williams W, Davies BH eds. 8th International Conference on Sarcoidosis and Other Granulomatous Diseases. Alpha Omega Publishing Ltd, Cardiff 1978; 195-200.

50. Nowack D, Goebel KM. Genetic aspects of sarcoidosis. Class II histocompatibility antigens and a family study. Arch Intern Med 1987; 147: 481-483.

51. Pasturenzi L, Martinetti M, Cuccia M, Cipriani A, Semenzato G, Luisetti $M$ and the Pavia-Padua Sarcoidosis Study Group. HLA class I, II, III polymorphisms in Italian patients with sarcoidosis. Chest 1993; 104: 1170-1175.

52. Kunikane H, Abe S, Tsuneta Y, et al. Role of HLA-DR antigens in Japanese patients with sarcoidosis. Am Rev Respir Dis 1987; 135: 688-691.

53. Ina Y, Takada K, Yamamoto M, Morishita M, Senda Y, Torii Y. HLA and sarcoidosis in the Japanese. Chest 1989; 95: 1257-1261.

54. Odum N, Milman N, Jakobsen BK, Georgsen J, Svejgaard A. HLA class II (DR, DQ, DP) in patients with sarcoidosis: evidence of and increase frequency of DRw6. Exp Clin Immunogenet 1991; 8: 227-232.

55. Olerup O, Hillert J. HLA class II associated genetic susceptibility in multiple sclerosis: a critical evaluation. Tissue Antigens 1991; 38: 1-15.

56. Kunikane $\mathrm{H}$, Abe S, Yamaguchi E, et al. Analysis of restriction fragment length polymorphism for the HLADR gene in Japanese patients with sarcoidosis. Thorax 1994; 49: 573-576.

57. Ishihara $\mathrm{M}$, Ohno $\mathrm{S}$, Ishida $\mathrm{T}$, et al. Molecular genetic studies of HLA class II alleles in sarcoidosis. Tissue Antigens 1994; 43: 238-241.

58. Berlin M, Fogdell-Hahn A, Olerup O, Eklund A, Grunewald J. HLA-DR predicts the prognosis in Scandinavian patients with pulmonary sarcoidosis. Am J Respir Crit Care Med 1997; 156: 1601-1605.

59. Richeldi L, Sorrentino R, Saltini C. HLA-DPB1 glutamate 69: a genetic marker of beryllium disease. Science 1993; 262: 242-244.

60. Saltini C, Sorrentino R, Richeldi L, Luisetti M, Bisetti A. Role of the HLA-DP gene in susceptibility to lung granulomas. Sarcoidosis 1993; 10: 171-172.

61. Maliarik MJ, Chen KM, Major ML, et al. Analysis of HLA-DPB1 polymorphisms in African-Americans with sarcoidosis. Am J Respir Crit Care Med 1998; 158-114.

62. Lympany PA, Petrek M, Southcott AM, Newman Taylor AJ, Welsh Kl, du Bois RM. HLA-DPB polymorphisms: Glu69 association with sarcoidosis. Eur J Immunogenet 1996; 23: 353-359.

63. Schürmann M, Bein G, Kirsten D, Schlaak M, MüllerQuernheim J, Schwinger E. HLA-DQB1 and HLA-DPB1 genotypes in familial sarcoidosis. Respir Med 1998; 92: 649-652.

64. Foley PJ, Lympany PA, Puscinska E, Zielinski J, Welsh
K1, du Bois RM. Analysis of MHC encoded antigenprocessing genes TAP1 and TAP2 polymorphisms in sarcoidosis. Am J Respir Crit Care Med 1999; 160: 1009_ 1014.

65. Trowsdale J, Hanson I, Mockridge I, Beck S, Townsend A, Kelly A. Sequences encoded in the class II region of the MHC related to the "ABC" superfamily of transporters. Nature 1990; 348: 741-743.

66. Glynne R, Powis SH, Beck S, Kelly A, Kerr LA, Trowsdale J. A proteasome related gene between the two ABC-transporter loci in the class II region of the human MHC. Nature 1991; 353: 1234-1237.

67. Ishihara $\mathrm{M}$, Ohno $\mathrm{S}$, Mizuki $\mathrm{N}$, et al. LMP7 polymorphism in Japanese with sarcoidosis and Behçet's disease. Hum Immunol 1996; 51: 103-105.

68. Ishihara M, Ohno S, Mizuki N, et al. Genetic polymorphisms of the major histocompatibility complexencoded antigenprocessing genes TAP and LMP in sarcoidosis. Hum Immunol 1996; 45: 105-110.

69. Ishihara M, Ohno S, Ishida T, et al. Analysis of allelic variation of the TAP2 gene in sarcoidosis. Tissue Antigens 1997; 49: 107-110.

70. Ishihara M, Ohno S, Ishida T, Naruse T, Inoko H. Genetic polymorphism in intron 6 of the LMP7 gene in Japanese and its association with sarcoidosis. Tissue Antigens 1997; 50: 650-653.

71. Finco O, Martinetti M, Dondi E, Luisetti M, Pasturenzi L, Cuccia M. Sarcoidosis and major histocompatibility complex genes with special emphasis on BF F subtypes. Complement Inflamm 1991; 8: 80-85.

72. Seitzer U, Swider C, Stüber F, et al. Tumor necrosis factor alpha promoter gene polymorphism in sarcoidosis. Cytokine 1997; 9: 787-790.

73. Richeldi L, Losi M, Pelori F, Luisetti M, Martinetti M, Saltini C. Role of the tumor necrosis factor $\alpha-308$ polymorphism in pulmonary sarcoidosis. Eur Respir $J$ 1997; 10: Suppl. 25, 98s.

74. Ishihara $\mathrm{M}$, Ohno $\mathrm{S}$, Ishida $\mathrm{T}$, et al. Genetic polymorphisms of the TNFB and HSP70 genes located in the human major histocompatibility complex in sarcoidosis. Tissue Antigens 1995; 46: 59-62.

75. Smith MJ, Turton CWG, Mitchell DN, Turner-Warwick M, Morris LM, Lawler SD. Association of HLA B8 with spontaneous resolution in sarcoidosis. Thorax 1981; 36: 296-298.

76. Hedfors E, Lindstrom F. HLA-B8/DR3 in sarcoidosis. Correlation to acute onset disease with arthritis. Tissue Antigens 1983; 22: 200-203.

77. Abe S, Yamaguchi E, Makimura S, Okazaki N, Kunikane $\mathrm{H}$, Kawakami Y. Association of HLA-DR with sarcoidosis. Correlation with clinical course. Chest 1987; 92: 488-490.

78. Ishihara M, Ishida T, Mizuki H, Ando H, Ohno S. Clinical features of sarcoidosis in relation to HLA distribution and HLA-DRB3 genotyping by PCR-RFLP. Brit J Ophthalmol 1995; 79: 322-325.

79. Takashige N, Naruse TK, Matsumori A, et al. Genetic polymorphisms at the tumour necrosis factor loci (TNFA and TNFB) in cardiac sarcoidosis. Tissue Antigens 1999; 54: 191-193.

80. Gardner J, Kennedy HG, Hamblin A, Jones E. HLA associations in sarcoidosis: a study of two ethnic groups. Thorax 1984; 39: 19-22.

81. Moller DR. T-cell receptor genes in sarcoidosis. Sarcoidosis Vasc Diffuse Lung Dis 1998; 15: 158-164.

82. Rybicki BA, Maliarik MJ, Mavitz E, et al. The influence of $\mathrm{T}$ cell receptor and cytokine genes on sarcoidosis 
susceptibility in African Americans. Hum Immunol 1999; 60: 867-874.

83. Grunewald J, Olerup O, Persson U, Berlin Öhm M, Wigzell $\mathrm{H}$, Eklund $\mathrm{A}$. T-cell receptor variable region gene usage by CD4+ and CD8+ T cells in bronchoalveolar lavage fluid and peripheral blood of sarcoidosis patients. Proc Natl Acad Sci USA 1994; 4965-4969.

84. Grunewald J, Hultman T, Bucht A, Eklund A, Wigzell H. Restricted usage of $\mathrm{T}$ cell receptor $\mathrm{V} \alpha / \mathrm{J} \alpha$ gene segments with different nucleotide but identical amino acid sequences in HLA-DR3+ sarcoidosis patients. Mol Med 1995; 1: 287-296.

85. Grunewald J, Shigematsu M, Nagai S, et al. T-cell receptor $\mathrm{V}$ gene expression in HLA-typed Japanese patients with pulmonary sarcoidosis. Am J Respir Crit Care Med 1995; 151: 151-156.

86. Grunewald J, Berlin M, Olerup O, Eklund A. Lung Thelper cells expressing T-cell receptor AV2S3 associate with clinical features of sarcoidosis. Am J Respir Crit Care Med 2000; 161: 814-818.

87. Eklund A, Grunewald J. The riddle of sarcoidosis: have novel techniques brought any new insights as to the causative agent? J Intern Med 1996; 240: 59-62.

88. Hunninghake GW, Crustal RG. Mechanisms of hypergammaglobulinemia in pulmonary sarcoidosis. $J$ Clin Invest 1981; 67: 86-92.

89. Newill CA, Johna CJ, Cohen BH, Diamond EL, Bias WB. Sarcoidosis, HLA and immunoglobulin markers in Baltimore blacks. In: Chrètien J, Marsac J, Saltiel JC eds. Sarcoidosis and Other Granulomatous Diseases. Paris, Pergamon Press, 1983; pp. 253-256.

90. Martinetti M, Dugoujon J-M, Tinelli C, et al. HLA- GM/ $\mathrm{KM}$ interaction in sarcoidosis. Suggestions for a complex genetic structure. Eur Respir J 2000; 16: 74-80.

91. Allen RKA. Angiotensin-converting enzyme. In: James DG, ed. Sarcoidosis and Other Granulomatous Disorders. New York, Marcel Dekker, 1994; pp. 529-564.

92. Okabe T, Fujisawa M, Yotsumoto H, Takaku F, Lanzillo JJ, Fanburg BL. Familial elevation of serum angiotensin converting enzyme. $Q J \mathrm{Med} 1985$; 216: 55-61.

93. Luisetti M, Martinetti M, Cuccia M, et al. Familial elevation of serum angiotensin converting enzyme activity. Eur Respir J 1990; 3: 441-446.

94. Rigat B, Hubert C, Alhenc-Gelas F, Cambien F, Corvol P, Soubier F. An insertion/deletion polymorphism in the angiotensin-I-converting enzyme gene accounting for half the variance of serum enzyme levels. J Clin Invest 1990; 86: $1343-1346$.

95. Arbustini E, Grasso M, Leo G, et al. Polymorphism of angiotensin-converting enzyme gene in sarcoidosis. Am J Respir Crit Care Med 1996; 153: 851-854.

96. Maliarik MJ, Rybicki BA, Malvitz E, et al. Angiotensinconverting enzyme gene polymorphism and risk of sarcoidosis. Am J Respir Crit Care Med 1998; 158: $1566-1570$.

97. Pietinalho A, Furuya K, Yamaguchi E, Kawakami Y, Selroos $\mathrm{O}$. The angiotensin converting enzyme DD gene is associated with poor prognosis in Finnish sarcoidosis patients. Eur Respir J 1999; 13: 723-726.

98. Tomita H, Ina Y, Sugiura Y, Sato S, et al. Polymorphism in the angiotensin-converting enzyme (ACE) gene and sarcoidosis. Am J Respir Crit Care Med 1997; 156: 255259.

99. Furuya K, Yamaguchi E, Itoh A, et al. Deletion polymorphism in the angiotensin I converting enzyme (ACE) as a genetic risk factor for sarcoidosis. Thorax 1996; 51 : 777-780
100. Niimi $\mathrm{T}$, Tomita $\mathrm{H}$, Sato $\mathrm{S}$, et al. Bronchial responsiveness and angiotensin-converting enzyme gene polymorphism in sarcoidosis patients. Chest 1998; 114: 495-499.

101. Takemoto Y, Sakatani M, Takami S, et al. Association between angiotensin II receptor gene polymorphism and serum angiotensin converting enzyme (SACE) activity in patients with sarcoidosis. Thorax 1998; 53: 459-462.

102. Car BD, Meloni F, Luisetti M, Semenzato G, Gialdroni Grassi G, Walz A. Elevated IL-8 and MCP-1 in the bronchoalveolar lavage fluid of patients with idiopathic pulmonary fibrosis and pulmonary sarcoidosis. $\mathrm{Am} \mathrm{J}$ Respir Crit Care Med 1994; 149: 655-659.

103. Kostrikis LG, Huang Y, Moore JP, et al. A chemokine receptor CCR2 allele delays HIV-1 disease progression and is associated with a CCR5 promoter mutation. Nature Med 1998; 4: 350-353.

104. Hizawa N, Yamaguchi E, Furuya K, Jinushi E, Ito A, Kawakami Y. The role of the C-C chemokine receptor 2 gene polymorphism V641 (CCR2-641) in sarcoidosis in a Japanese population. Am J Respir Crit Care Med 1999; 159: 2021-2023.

105. Raphael SA, Blau EB, Zhang WH, Hsu SH. Analysis of a large kindred with Blau syndrome for HLA, autoimmunity, and sarcoidosis. Am J Dis Child 1993; 147: 842-848.

106. James DG. A comparison of Blau's syndrome and sarcoidosis. Sarcoidosis 1994; 11: 100-101.

107. Willoughby JMT, Mitchell DN, Wilson JD. Sarcoidosis and Crohn's disease in siblings. Am Rev Respir Dis 1971; 104: 249-254

108. Grönhagen-Riska C, Fyhrquist F, Hortling L, Koskimies S. Familial occurrence of sarcoidosis and Crohn's disease. Lancet 1983; i: 1287-1288.

109. Bambery P, Kaur U, Bhusnurmath SR, Dilawari JB. Familial idiopathic granulomatosis: sarcoidosis and Crohn's disease in two Indian families. Thorax 1991; 46: 919-921.

110. Rybicki BA, Maliarik MJ, Bock $\mathrm{CH}$, et al. The Blau syndrome gene is not a major risk factor for sarcoidosis. Sarcoidosis Vasc Diffuse Lung Dis 1999; 16: 203-208.

111. Schürmann M, Müller-Myhsok B, Muller-Quernheim J, Schwinger E. Results from a whole genome search for predisposing genes in sarcoidosis. Sarcoidosis Vasc Diffuse Lung Dis 1999; 16 (suppl 1): 20 (abst).

112. Rizzato G, Montemurro L. The locomotor system. In: James DG, ed. Sarcoidosis and Other Granulomatous Disorders. New York, Marcel Dekker Inc., 1994; pp. 349373.

113. Niimi T, Tomita H, Sato S, et al. Vitamin D receptor gene polymorphism in patients with sarcoidosis. Am J Respir Crit Care Med 1999; 160: 1107-1109.

114. Bombieri C, Benetazzo MG, Saccomani A, et al. Complete mutational screening of the CFTR gene in 120 patients with pulmonary disease. Hum Genet 1998; 103: 718-722.

115. Bombieri $\mathrm{C}$, Luisetti M, Belpinati $\mathrm{F}$, et al. Increased frequency of CFTR gene mutations in sarcoidosis: a casecontrol association study. Eur J Hum Genet 2000; 8: 717720 .

116. Tiwai JL, Terasaki PI. HLA and Disease Associations. New York, Springer-Verlag, 1985.

117. Judson MA, Baughman RP, Teirstein AS, Terrin ML, Yeager H Jr, ACCESS Research Group. Defining organ involvement in sarcoidosis: the ACCESS proposed instrument. Sarcoidosis Vasc Diffuse Lung Dis 1999; 16: $75-86$. 